\title{
A ZONA DE CISALHAMENTO DO RIO PARAÍBA DO SUL NAS VIZINHANÇAS DE TRÊS RIOS (RJ): UMA ANÁLISE DA DEFORMAÇÃO DADA POR ALGUMAS FEIÇÕES ESTRUTURAIS
}

\author{
HENRIQUE DAYAN* e JOÃO VICENTE ALFANO KELLER**
}

\begin{abstract}
THE SHEAR ZONE OF THE PARAIBA DO SUL RIVER IN THE NEIGHBOURHOOD OF TRES RIOS (RJ): AN ANALYSIS OF DEFORMATION BASED UPON STRUCTURAL CRITERIA A small segment of the shear zone of the Paraiba do Sul river, in the neighbourhood of Tres Rios, state of Rio de Janeiro, Brazil, is investigated here. A strain analysis of this area is made here, based on modern shear criteria. Grain shape analysis of extremely stretched quartz ribbons reveals highly oblate pancake ellipsoids with $\mathrm{XZ}$ axes near the horizontal plane and suggesting wrench type dextral movements, along this zone. Field evidences suggest a symmetry of structures, relative to the main central mylonite zone. It is also suggested here that the studied area presents two parallel mylonitic zones. Vertical movements of blocks are interpreted as due to transpressional effects generated in this fault area. Fold mullions and rodding are interpreted here as being formed by superposition of strain on a previous fabric present in these rocks. An apparent volume change inside one of the mylonitic zones is revealed by the strain analysis. Its implications are discussed in the light of the field evidences.
\end{abstract}

\begin{abstract}
RESUMO Um pequeno segmento da zona de cisalhamento do Rio Paraíba do Sul, nas vizinhanças de Três Rios, Estado do Rio de Janeiro, Brasil, é aqui investigado. Uma análise de deformacão dessa área foi levada a cabo com base em critérios de cisalhamento conhecidos atualmente. A análise da forma de fitas de quartzo revela elipsóides de formas extremamente oblatas, com eixos $\mathrm{XZ}$ perto do plano horizontal, sugerindo movimento transcorrente de sentido dextral ao longo dessa zona. Evidências de campo sugerem uma simetria de estruturas relativas à zona (central) milonítica principal. Também sugere-se aqui que a área de estudo apresenta duas zonas miloníticas paralelas. Movimentos verticais de blocos são interpretados como resultado de efeitos transpressionais gerados nessa zona de falhas. Estruturas lineares do tipo fold mullions e rods são aqui interpretadas como sendo formadas por superposição de deformação em trama preteritamente presente nessas rochas. Uma aparente mudança volumétrica no interior dessas zonas miloníticas é evidenciada pela análise de deformação. Suas implicaçôes sâo discutidas à luz de evidências de campo.
\end{abstract}

INTRODUÇÃO O bordo noroeste do Estado do Rio de Janeiro e as partes vizinhas do Estado de Minas Gerais apresentam extensas faixas alinhadas que exibem feições de intensa concentraçâo de deformaçôes localizadas, identificadas como zonas de cisalhamento. Entre todas essas faixas destacase uma denominada Lineamento de Além-Paraíba (Almeida et al. 1975).

Observações feitas em mapas (Fonseca et al. 1978), em imagens de satélite ou mesmo nas de radar levam um observador a constatar que é notável a expressão da continuidade desse lineamento (Campanha 1980), o qual sugere a captura do curso do Rio Paraiba do Sul, em trecho praticamente retilineo, compreendido entre as cidades de Andrade Pinto (RJ) e Itaocara (RJ), com aproximadamente $150 \mathrm{~km}$.

$\mathrm{Na}$ opinião de Hasui et al. (1983); tal lineamento não está somente restrito às localidades supramencionadas mas ainda apresenta relações de continuidade, rumo $\mathrm{SW}$, ligando-se a complexos de falhas no Estado de São Paulo, adentrando ainda no Estado do Paraná.

Observações em imagens recentes (Landsat e Radambrasil), do trecho ao norte de Três Rios (RJ), revelam tambem a existência de outros lineamentos associados, os quais se ramificam mediante traçados semelhantes ao de curvas parabólicas derivadas assintoticamente a partir do Lineamento de AlémParaíba (Brenner et al. 1980). As concavidades dessas ramificaçōes estão voltadas para o sentido NW (Fig. 1). Nas imagens de radar, uma daquelas ramificações dessa estrutura linear parece ter conexão com o Lineamento de Guaçuí (Fonseca et al. 1978, Campanha 1980, Lammerer 1987), localizado no Estado do Espírito Santo.

As investigaçōes nesta região datam do século passado (Derby 1880), mas foi de Rosier $(1965,1967)$ e de Ebert $(1967,1968)$ que auferimos importantes observações de cunho regional.
Na presente década, esta região continua atraindo atençôes e daí as contribuições de Campanha (1980, 1981), Brenner et al. (1980), Barbosa et al. (1981), Oliveira (1983), Reis (1982), Hasui (1983), Sadowski (1983) e Campanha \& Ferrari (1984).

A geologia da Folha Três Rios (base do IBGESE.23-Q-11-2, escala 1:50.000) foi elaborada para o DRM em 1982 graças aos serviços da Geosol, sendo seus correspondentes mapas relatórios até hoje inéditos.

O Lineamento de Além-Paraíba é, no presente estudo, encarado da maneira mais simplista, como uma zona de cisalhamento onde predominaram deformaçōes plásticas (isto é, no sentido de ductile shear zone) nos moldes definidos por Ramsay \& Graham (1970) e revisto posteriormente por Ramsay (1980). A área-alvo dessa contribuição (Fig. 1) desenvolveu-se em duas seções: I. a primeira com cerca de $15 \mathrm{~km}$ de extensão (ao longo da rodovia BR-040), a qual corta obliquamente essa zona de falhas; II. a segunda seção nas áreas vizinhas à cidade de Três Rios abrangendo as margens do Rio Paraíba do Sul em um percurso com cerca de $7 \mathrm{~km}$ (Fig. 2).

A presente investigação objetivou especificamente o estudo e a aplicaçấo de técnicas com cunho estrutural, no intuito de inferir a natureza e o sentido do movimento dos blocos cortados por zonas de falhas. Tratou-se de quantificar deformaçōes e interpretar algumas feiçöes estruturais com base em mecanismos e modelos de deformaçóes em voga na presente data.

MÉTODOS E RESULTAdOS Colocação de problemas A localização da área de trabalho (Fig. 2) abrange um segmento do Lineamento de Além-Paraíba e partes vizinhas, a norte e a sul, nas imediações de Três Rios (RJ). A área apresenta uma simetria de estruturas em relação à zona central, ocupada pela calha do Rio Paraíba do Sul. Em ambos os 


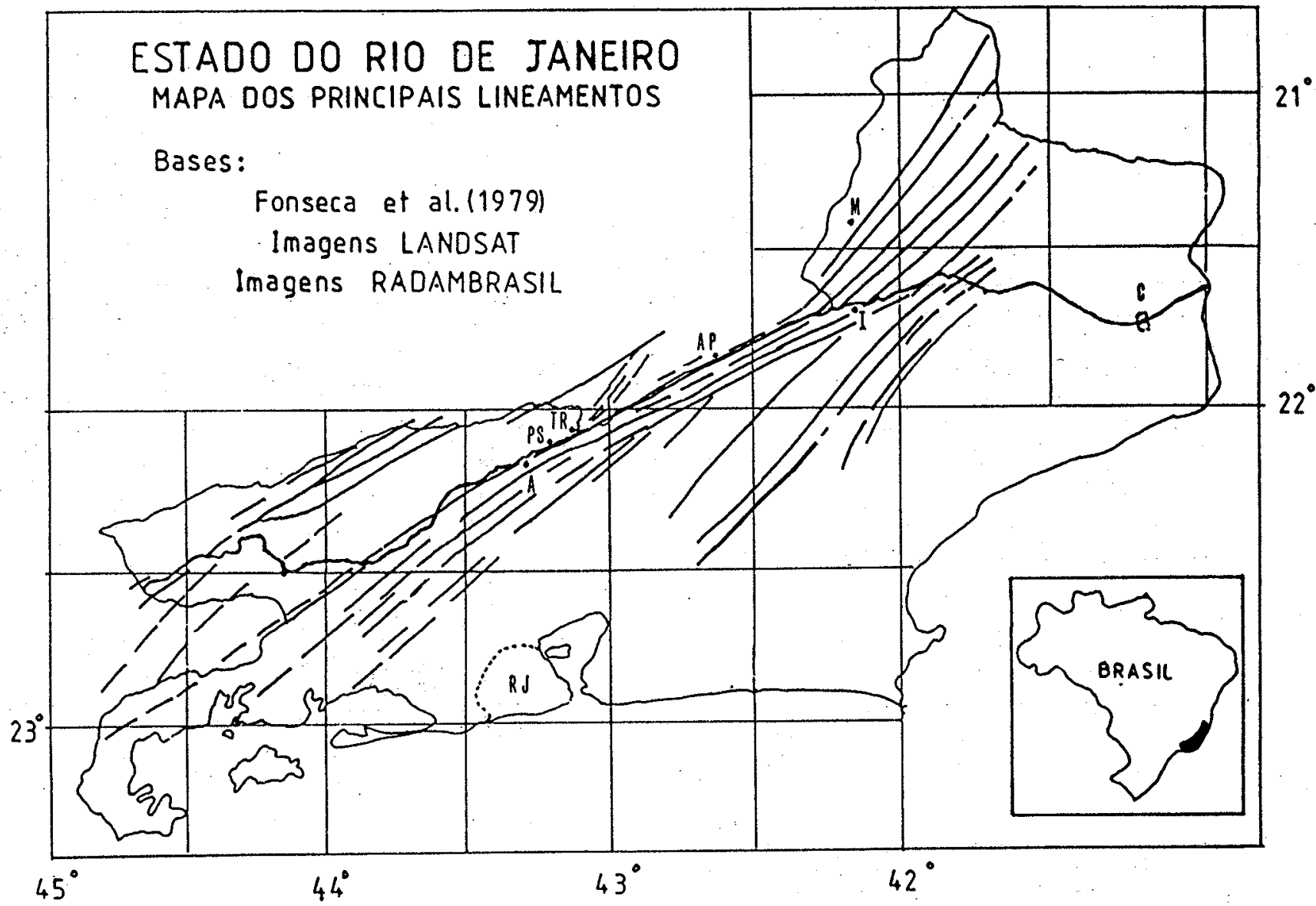

Figura 1 - Mapa geográfico do Estado do Rio de Janeiro, com a localização dos principais lineamentos. Compilação baseada em Fonseca et al. 1979, imagens de satélite (Landsat 1975), imagens de Radar (Projeto Radambrasil). Janela no canto inferior direito posiciona o estado no mapa do território brasileiro. As seguintes letras assinalam as posiçóes geográficas das seguintes localidades. RJ, Rio de Janeiro; A, Andrade Pinto; PS, Paraiba do Sul; AP, Além-Paraiba; I, Itaocara; M, Miracema; e C, Campos. O Rio Paraíba do Sul está representado pelo traço sinuoso que corta o Estado do Rio de Janeiro na direção WSW-ENE

Figure 1 - Geographic map of the state of Rio de Janeiro showing its main lineaments. Compilation from Fonseca et al. 1979, satelite images (Landsat 1975), radar images (Project Radambrasil). Map inset shows the location of this area within the Brazilian territory. The following localities are represented in the main map by the initials: RJ, Rio de Janeiro; A, Andrade Pinto; PS, Parafba do Sul; AP, Além-Parafba; I, Itrocara; M, Miracema; and C, Campos. The Parafba do Sul river is represented by the convoluted trace running along the WSW-ENE direction

extremos da área nota-se o desenvolvimento de estruturas lineares (mullions a norte, rods a sul), paralelas às direções das charneiras das dobras, orientadas segundo a direçáo N60E.

À medida que se aproxima da zona central (Fig. 2), modificam-se as características da foliação gnáissica, que se torna mais finamente espaçada, acompanhada de um progressivo vergamento para a atitude vertical. Nota-se tambem a existência de uma lineação sub-horizontal nesta foliação, que adquire características miloníticas na parte central da figura em questão. As rochas aí têm aspecto de proeminentes tectonitos$\mathrm{S}$, com foliação dada por bandamento milimétrico uniformemente espaçado com atitude vertical. Eixos de dobras e uma lineação mineral penetrativa têm atitudes sub-horizontais. Todos os elementos ou partículas ditas "rígidas" (isto $\epsilon$, inclusões máficas, porfiroclastos etc.) direcionam suas maiores dimensões longitudinais para a atitude de sub-horizontalidade e apresentam-se contidos na foliação.

Os traços proeminentes daqueles lineamentos arqueados referidos na "Introduçāo" estão fora dos limites da figura 2 , entretanto essas estruturas curvas estão relacionadas com o desenvolvimento das estruturas regionais de grande parte da área do Estado do Rio de Janeiro. Para mençóes a determina- dos mecanismos relacionados ao desenvolvimento desses lineamentos, definem-se esses domínios segundo nomenclatura proposta por Woodcock \& Fischer (1986): a. segmentos retilíneos de falhas transcorrentes são denominados straights ou retas, enquanto b. aqueles traços ramificados com forma arqueada são referidos como curvas oblíquas (oblique bends). As últimas estruturas têm particular importância e são subdivididas em I. curvas de alívio ou relaxamento (releasing bends) e II. curvas de restrição (restraining bends). A caracterização da condição de relaxamento ou restrição varia em função do sentido do movimento dos blocos (isto $\epsilon$, levógiro ou dextrógiro) relativamente ao traçado das curvas, em $\mathrm{S}$ ou $\mathrm{Z}$

Descrição e setorizaçằo da área estudada A área ilustrada pela figura 2 está subdividida em setores rotulados de A a I. A maior parte desses setores faz parte de um roteiro de excursão apresentado por Campanha \& Ferrari (1984). O presente trabalho visou aplicar novos conceitos relacionados a qualificação de movimentos e à quantificação de deformações em rochas.

No campo, constata-se que as litologias evidenciam a presença de faixas com distintas intensidades de deformaçăo. 


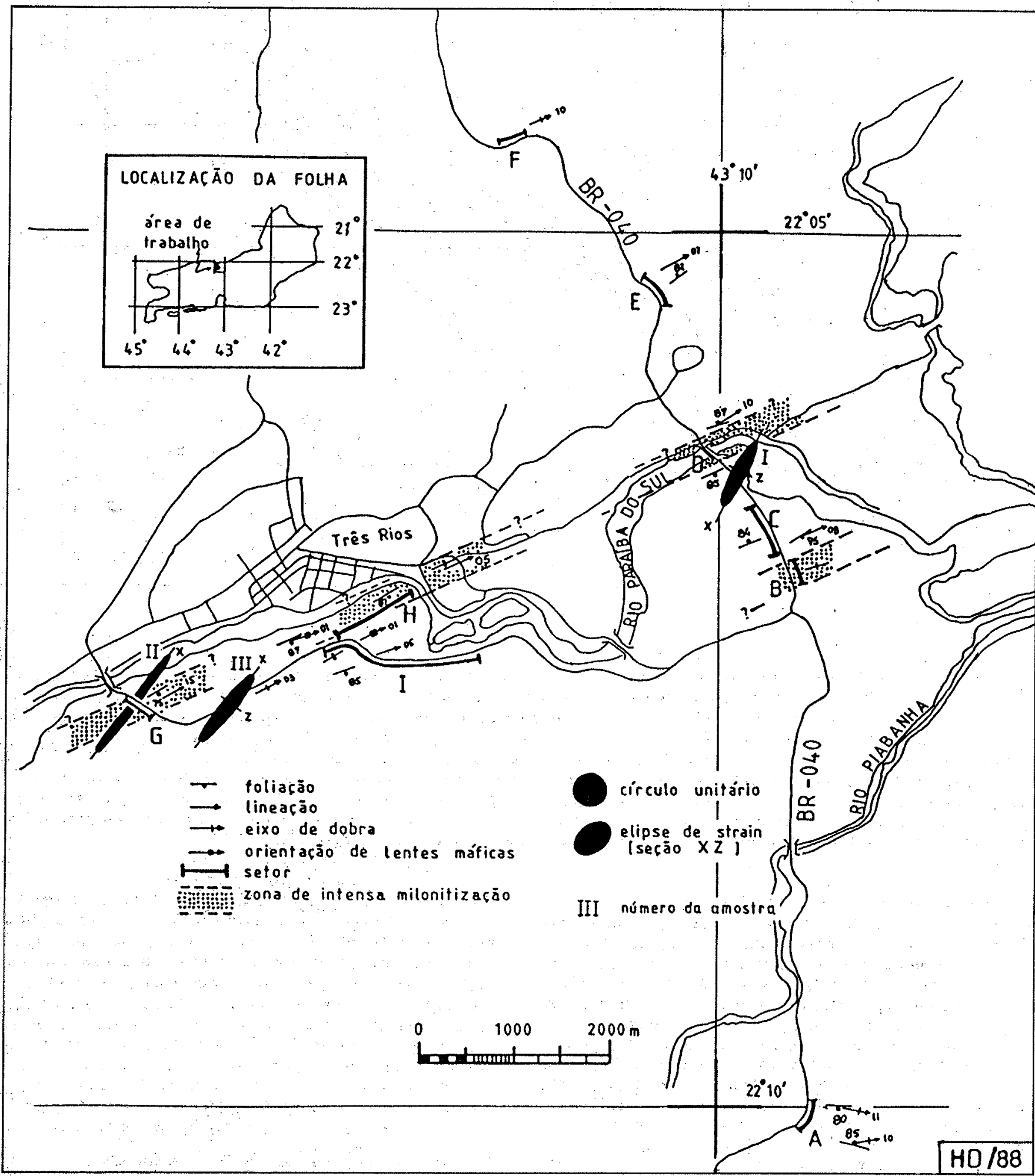

Figura 2 - Mapa da área de estudo, localizada nas cercanias de Três Rios (RJ). Janela no canto superior esquerdo com a localização da área. Letras maiúsculas. (A-I) delimitam os setores discutidos no texto. Algumas feiçôes estruturais foram plotadas nos locais devidos. Elipses representam e posicionam as aproximadas atitudes das seçöes XZ dos elipsóides discutidos no texto, enquanto o ctrculo unitário, de mesma área que as elipses, é o referencial no estado náo deformado

Figure 2 - Study area located in the neighbourhood of the city of Tres Rios (RJ). Map inset shows the location of this area within the state of Rio de Janeiro. Initials A-I locate the different sectors discussed in the text. Map legend shows the representation of some structures seen in this area. Elipses represent the attitudes of the XZ-principal sections of the ellipsoids discussed in the text. Unit circle is the reference datum for the undeformed state 
A morfologia das rochas nessas faixas têm características estruturalmente similares ainda que variem seus tipos litologicos. A conspícua presença de foliação finamente espaçada, extremamente planar, com paralelismo de minerais, bandas e inclusōes, é marcadamente contínua ao longo das mesmas. Ainda no plano dessa foliação, subvertical em todos os domínios mais deformados, existe somente uma persistente lineação com atitude muito próxima da horizontal.

É possível observar-se, à vista desarmada, que as rochas apresentam bandamentos composicionais, gradando não s6 na natureza dos mesmos bem como nas espessuras e nos espaçamentos, de acordo com a composição litológica e as intensidades das deformaçōes. A existência de fases minerais com granulometria que variam de fina, média a grossa (porfiroclastos) é observada constantemente nessas zonas.

Ao microscópio, as microestruturas também variam, consoante o litótipo e o grau de deformação. As rochas exibem feiçōes de recristalização de grãos com dimensóes reduzidas, quando comparadas aos clastos com dimensóes muito variadas. Mostram clara orientação preferencial dada pelo alinhamento de minerais, sejam eles eqüidimensionais ou de hábitos tabulares, elongados, aciculares e agregados de minerais, de modo a constituírem bandas extremamente paralelas. Além disso, apresentam gradações na razão porfiroclasto/ "matriz recristalizada" variando de 0,2 a 0,99 .

Baseados, pois, nas características macro, meso e microscópicas, e tendo em mente a problemática discutida por White (1982), Chester et al. (1986) e os conceitos de Ramsay \& Graham (1970) e Ramsay (1980), pode-se definir, como já fizera Campanha $(1980,1981)$, esses domínios como faixas de deformaçốes localizadas, nas quais as microestruturas estariam em perfeito acordo com definição de milonito ou milonitização e suas variações, segundo a proposta de White (1982).

Levando-se em conta o exposto anteriormente e os propositos do trabalho em pauta, refere-se doravante ao Lineamento de Além-Paraíba (Almeida et al. 1975) especificamente como Zona de Cisalhamento do Rio Paraíba do Sul (ZCRPS) de modo a caracterizar a natureza do estudo.

Atravessando-se a área coberta pela figura 2 , no sentido de sul para norte, nota-se que a foliação das rochas gnáissicas passa gradativamente para uma verticalização e adquire lineação mesoscópica (mineral ?), penetrativa, sub-horizontal, orientada segundo $20 \%$ N65E. Dobras do tipo horizontalnormal (Turner \& Weiss, 1963) e núcleos de natureza cálciosilicática têm aparência de rodse ainda domínios que se assemelham a mullions exibem orientação paralela à lineação acima descrita (setor A, Fig. 2).

$\mathrm{Na}$ altura da Pedreira Tabaiara (setor B) ocorre a primeira faixa milonítica visível nos afloramentos existentes. Pode-se observar que: I. a foliação é extremamente paralelizada, quase vertical, orientada segundo N70E. Variaçöes morfologicas locais mostram a existência de microbandamentos com porfiroblastos simétricos e assimétricos; II. presença de lineação (mesoscópica) sub-horizontal que pode ser vista a distâncias de até $100 \mathrm{~m}$ do afloramento; III. dobras, certamente redobradas, com grau de fechamento do ângulo interflanco, ao redor de $15^{\circ}$ e eixos sub-horizontais; IV . variaçōes litológicas mediante finas interdigitações colocaram biotita-hornblenda gnaisses cinzentos em contato com finas franjas de coloração rósea de microclina quartzo gnaisse, e até com rochas mais escuras, com composição charnockítica. Observações dessas amostras de mão denotam que esses efeitos de transposição de foliação microespaçada conduzem à obliteração de pretéritos aleitamentos e/ou bandamentos composicionais.

Ao longo da estrada BR-040, no domínio do setor C (Fig. 2), verifica-se uma diminuição acentuada no grau da deformação. As rochas nesse trecho não têm as mesmas características miloníticas do setor $\mathrm{B}$, exibindo bandamentos mais espessos (ordem de vários centímetros), verticalizados e nítidas variaçōes nos tipos litológicos. A população das dobras aumenta e elas podem ser classificadas como horizontais-normais. Observam-se, ainda localmente, morfologias muito parecidas a migmatitos com cerca de $50 \%$ de material lucocrático (neossomático ?). A gră local é média, destacando-se, por vezes, a presença de cordierita com até $5 \mathrm{~cm}$ de diâmetro. Corpos de rochas máficas, abundantes até nas faixas miloníticas, são aqui encontrados também.

Para Campanha (1980, Fig. 2), o trecho que aqui se subdivide em setores $\mathrm{B}$ e $\mathrm{C}$ é englobado em uma única faixa denominada Zona Principal de Deformação. No campo, tem-se a nítida impressão de que as rochas da Pedreira Tabaiara (setor B) se apresentavam consideravelmente mais deformadas que as aflorantes ao longo do trecho adjacente a norte, daí a presente caracterização (isto $\hat{E}$, o setor $\mathrm{C}$ ).

Nova faixa de intensa deformação configura-se nas rochas localizadas a $100 \mathrm{~m}$ da extremidade sul da ponte sobre o Rio Paraíba do Sul (setor D). Este domínio estende-se pelo menos ate $150 \mathrm{~m}$ além da extremidade norte da referida ponte. Essa faixa é nitidamente milonítica e pode ser inspecionada nos inúmeros lajedos às margens do referido rio. No entender de Campanha (1980, Fig. 2), esta é a faixa "nas quais supostamente concentraram-se os movimentos transcorrentes tardios".

Prosseguindo ainda na BR-040, rumo norte, verifica-se uma escassez de afloramentos por cerca de $2 \mathrm{~km}$, tomados a partir do limite norte do setor $\mathrm{D}$. Distinguem-se claramente no setor E (Fig. 2), e por um percurso de cerca de $300 \mathrm{~m}$, afloramentos que evidenciam nova faixa de deformação, porém desprovida, até o quanto sabemos, de feições de milonitização. Essa terceira franja apresenta aumento progressivo da deformação no sentido de sul para norte. Essa faixa recebeu apropriada denominação de Zona de Transição (Campanha 1980).

As primeiras rochas aflorantes na porção sul do setor $\mathrm{E}$ são biotita-hornblenda gnaisses de grã grossa, por vezes com estruturas estromáticas, apresentando dobras próximas do tipo vertical-normal e ângulos interflancos ao redor de $70^{\circ}$. Essas características mudam progressivamente rumo norte e no espaço de cerca de $50 \mathrm{~m}$ observa-se passagem da foliação para a atitude vertical, aquele espesso bandamento gnáissico adquire progressivamente um fino espaçamento (centimétrico a milimétrico) e desenvolve-se aí uma nítida lineação mesoscópica, penetrativa e com constante atitude sub-horizontal.

Esse trecho exibe inúmeros núcleos de rochas cálcio-silicáticas, as quais denotam giro de blocos possivelmente ao longo da foliação. Essas rochas cálcio-silicáticas, que se assemelham às encontradas no setor $A$, têm colorações esverdeadas (tremolita-actinolita) ou branco-leitosa. Conforme a orientação da seção observada verifica-se, com freqüência, a presença desses aglomerados de cor verde, com formas boudinadas simétricas e assimétricas, estando estas caudas-de-boudins (boudin-tails) contidas naquela foliação verticalizada. $O$ maior desses núcleos cálcio-silicáticos encontra-se no setor $E$ e seu giro sugere movimentos relativos na vertical.

No setor F (Fig. 2) aparecem rochas com características bem distintas das encontradas nas faixas precedentes $E, D$ e B. São rochas com aspecto migmatítico exibindo partes máficas envoltas por domínios leucocráticos e têm formas dobradas contorcidas, claramente identificáveis como mullions, na verdadeira acepção de Holmes (1928) e Wilson (1953). O caráter linear e a imponência dessas marcantes estruturas fazem as mesmas se assemelharem a gigantescas pilastras tombadas, cujos diâmetros de suas seções elíptico-circulares têm dimensões de até $2 \mathrm{~m}$.

A orientação dessas feições lineares está em perfeita conformidade direcional com a lineação regional encontrada naquelas faixas miloníticas localizadas mais a sul. A atitude da foliação local varia de sub-horizontal a vertical, estando este conjunto de corrugamentos (mullions) a formar uma grande dobra assimétrica, quase revirada, com plano axial caindo para norte e vergência para sul. 
No trecho que liga o lado oeste de Três Rios à BR-040, sentido de $W$ para $E$, observam-se gradações nas intensidades de deformação. As rochas do setor $G$ (Fig. 2) apresentam características idênticas às encontradas no setor $\mathrm{D}$. $\mathrm{O}$ setor $\mathrm{H}$, leito seco do Rio Paraíba do Sul, é o sítio onde se encontram as rochas que presumivelmente denotam as feições das mais intensas deformações de todas as faixas aqui descritas. Em lâminas delgadas identificou-se a existência de ultramilonito em ponto de coleta ao norte do setor $\mathrm{G}$.

A faixa delimitada como setor I (Fig. 2) exibe uma gradual passagem para tipos litológicos menos deformados. Essa franja se assemelha estruturalmente à do setor $\mathrm{C}$. Tomando por base as atitudes uniformes da foliação e a constância de seu fino espaçamento, correlacionamos os setores $G, H$ e $D$ como pertinentes à mesma zona de intensa deformação plástica localizada (milonítica) e que presumivelmente estaria separada daquela outra zona milonítica a qual passaria pelo setor $B$ (Pedreira Tabaiara). Dessa forma propõe-se a existência de duas faixas miloníticas, paralelas e separadas entre si, pela fai$\mathrm{xa}$ que liga os setores $\mathrm{C} \mathrm{e} \mathrm{I}$.

Critérios de cisalhamento $\mathrm{O}$ atual estado de conhecimento permite afirmar que se podem usar os seguintes critérios:

I. Facóides assimétricos. São inúmeras as ocorrências e variados os domínios litologicos dessas feiçōes. As dimensões dessas partículas atingem a marca de uma ou mais dezenas de centímetros. Como característica comum, apresentam distribuição ao longo da foliação verticalizada, orientando suas (maiores) dimensões longitudinais segundo a direção N60E e caimentos sub-horizontais.

II. Grãos deslocados e rompidos. Agrupam-se neste item muitos dos diferentes enfoques dados para tais indicadores (White 1982, Passchier 1986, Cobbold \& Gapais 1987). A aplicação desses critérios não está restrita somente aos feldspatos - os mais abundantes de todos os clastos nesta zona mas existem possibilidades em potencial de se trabalhar também com piroxênios, anfibólios e sillimanita.

III. Rotação e deformação de indicadores do tipo xenólitos, inclusóes máficas, diques etc. Na verdade, encontram-se com freqüência corpos de coloração escura nos setores $\mathrm{C}, \mathrm{H}$ e I (Fig. 2). Núcleos de rochas cálcio-silicáticas são freqüentes nos domínios dos setores A e E. Entretanto não se pode tomar tais enclaves como indicadores diretos da deformação ocorrida na zona, pois está claro que, durante o(s) processo(s) de milonitização, esses corpos escuros teriam tido resistência à deformaçáo plástica, incrivelmente mais alta que as demais rochas que os circundam. Isso e evidente ao se constatar que mesmo nas zonas de mais intensa deformação (por exemplo, o setor $\mathbf{H}$ ) os corpos máficos ali presentes são os únicos domínios que possuem estruturas (planos-S) internas que năo foram transpostas e portanto discordam claramente da foliação milonítica adjacente.

Em suma, não se pode usar esses corpos à semelhança do que fizeram Ramsay \& Alison (1979) e Simpson \& Schmid (1983) nos Alpes suíços. Tais enclaves talvez fossem mais propicios para estudos de contrastes de ductilidade (Lisle et al. 1983, Ramsay 1982).

IV. Simetria de dobras intrafoliais. Como já se descreveu, a população das dobras nos milonitos e, aparentemente, inferior à das zonas externas às milonitizações. As poucas dobras encontradas nos milonitos têm atitudes de seus planos axiais na posição vertical e eixos sub-horizontais. Tais atitudes estão em plena concordância com as prediçōes teóricas (mecânicas) de que as dobras de idade pré ou sincrônicas com o movimento (último ?) relativo, no interior da shear zone, giram em direção ao plano XY do elipsóide de strain, enquanto os eixos das mesmas tendem ao paralelismo com o maior eixo principal X deste elipsóide (Bryant \& Reed 1969, Sanderson 1973, Hobbs et al. 1976, p. 194 e Fig. 6-15, Carreras et al. 1977, Bell
1978, Quinquis et al. 1978, Cobbold \& Quinquis 1980, Ramsay, Fig. 15, Dayan 1981).

Pode-se observar nas faixas miloníticas a presença de inúmeros ribbons de quartzo, com sutis dobras assimétricas em forma de Z, visando-se na direção do caimento para NE. Esses parcos resultados indicariam o desenvolvimento dessas dobras em um regime de cisalhamento simples, à semelhança daquelas cognominadas de contemporary folds por Escher \& Watterson (1974). A aceitação desse mecanismo simplista para o desenvolvimento da zona de cisalhamento indicaria movimentos dextrais dados em função do sentido do vórtice ao longo da zona de movimentação. Este critério é bastante relevante e merecedor de investigaçóes pormenorizadas nos trabalhos ora em andamento nesta área.

V. Elongaçóes e assimetrias de grãos de quartzo recristalizados. Devemos ao colega C: Psomopoulos a observação de minúsculas e aparentes lineaçóes minerais com dimensões na ordem de $1 \mathrm{~cm}$ x $0,1 \mathrm{~cm}$. Essas feições já haviam sido notadas anteriormente por Campanha (1980) e Campanha \& Ferrari (1984). Observa-se que são acículas alinhadas e contidas na foliação constituída de material translúcido, claramente identificável como sendo quartzo, envolto em uma matriz opaca homogênea e muito fina, com coloração e aspecto análogos aos dos porfiroclastos de feldspatos.

Essas feições microscópicas, extremamente alongadas, constituídas de quartzo e com aspecto de filetes são ilustradas na figura $6 \mathrm{~b}$. Numerosas e detalhadas observações de tais feições lineares revelaram valores de até $10 \times 0,1 \mathrm{~cm}$ (setor $\mathrm{H}$, Fig. 2). Foi dessa forma que se passou ao estudo e à analise da forma de grãos de quartzo (grain shape analysis), critério que constitui o tema central das deduções de cunho quantitativo neste artigo.

Os detalhes da técnica usada na obtenção da forma dos grãos de quartzo não têm lugar no presente estudo. Vale tão somente dizer que seguiu-se aqui a metodologia elaborada por Dayan (1981), a qual já foi também aplicada a rochas quartzíticas do sudeste do Estado de Minas Gerais por Dayan \& Baptista Filho (1984) e Dayan et al. (1987).

A essência do método consiste em seccionar a amostra para medições da forma dos grãos em três planos mutuamente ortogonais. Destes, retiram-se os valores finais das elipticidades (isto $\hat{\epsilon}$, um índice de forma) e as correspondentes orientaçōes dessas elipses, representativas de cada seção. Esta técnica de medição em duas dimensões é comumente referida como $R f$ / $\phi^{\prime}$ - diagrams (Ramsay 1967, Dunnet \& Siddans 1971, Ramsay \& Huber 1983, Lisle 1985), existindo para tanto inúmeros métodos. No presente estudo fez-se uso do método proposto por Shimamoto \& Ikeda (1976) pelas vantagens já discutidas em Dayan (1981).

Os resultados dessas três seções são os dados de entrada para o programa FITELI (Dayan 1981), que calcula as magnitudes e as atitudes dos três eixos principais do elipsóide representativo da amostra em estudo. Sendo a amostra de rocha coletada com orientação, $\epsilon$ tarefa trivial girar as atitudes desses três eixos do elipsóide contido na amostra para as coordenadas geográficas. Dessa forma, obtém-se a posição espacial do sólido e daí procede-se à análise dos resultados.

A tabela 1 contém os dados mais relevantes fornecidos na listagem dos resultados obtidos pelo programa FITELI enquanto os diagramas da figura 3 plotam as posições dos eixos principais das amostras em estudo. Conforme se observa na figura 2 , os três elipsóides pertencem a uma mesma franja milonítica. $O$ estereograma da figura $3 a$ demonstra que os eixos principais $\mathrm{X}, \mathrm{Y}$ e Z das amostras de número II e III (setor G) têm atitudes muito semelhantes, diferindo um pouco das atitudes encontradas para os eixos da amostra número $I$.

Podemos ter uma idéia simplificada do sentido do movimento ào longo da zona em estudo analisando as seções $X Z$ dos elips6ides em questão. Como ilustra a figura $4 b$, cada elipse em um regime de deformação por cisalhamento simples 

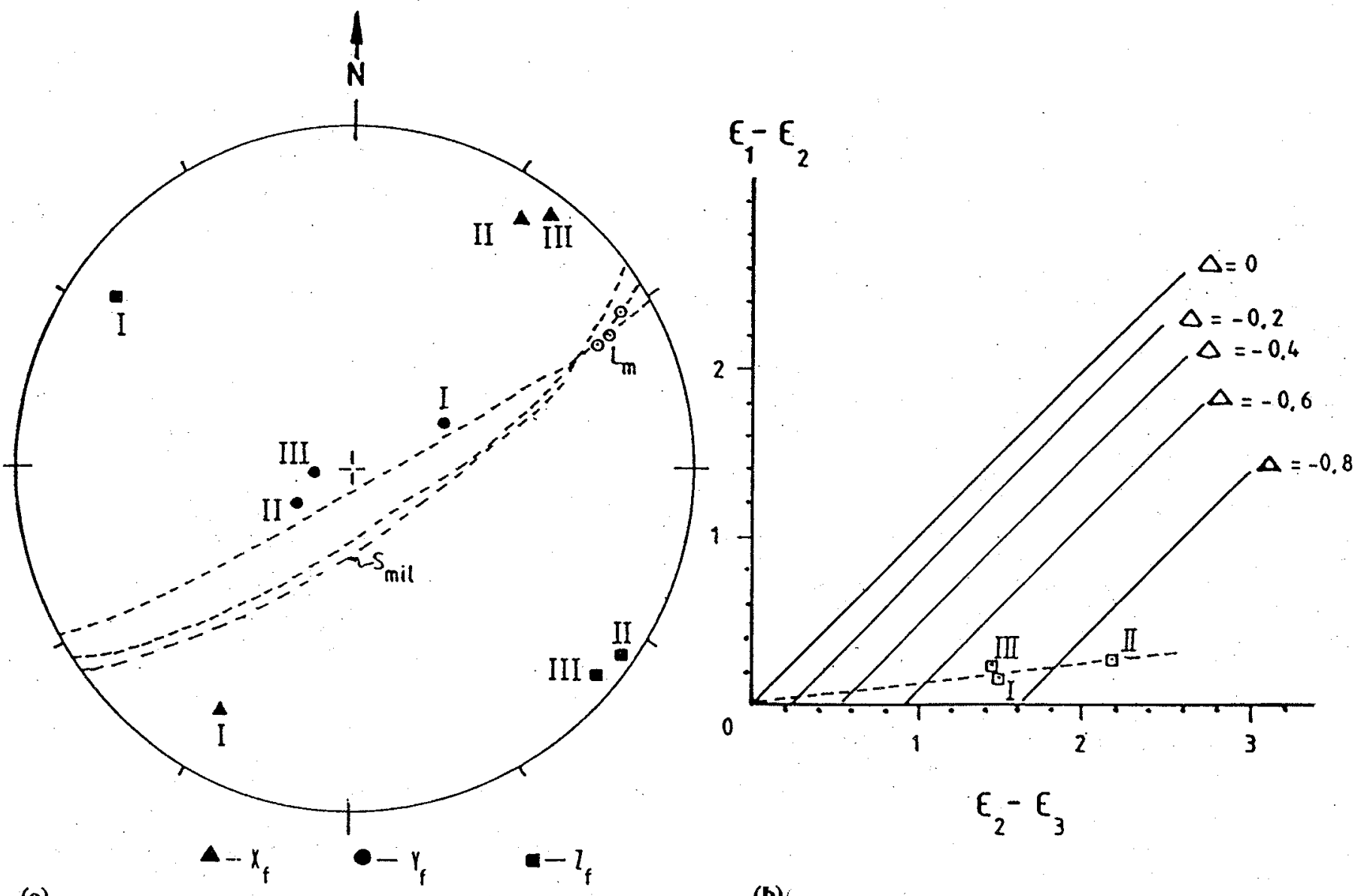

(a)

(b)

Figura 3 - a. Estereograma (hemisfério inferior) contendo as atitudes dos eixos principais dos elipsóides constantes da tabela 1 e representadas na figura 2. Legenda distingue e numera os três eixos de cada elipsóide. Linhas tracejadas ilustram as atitudes de representativas foliações miloníticas locais. Lm pósiciona medidas de lineações minerais. b. Versáo logarítmica do diagrama de Flinn (1962), também conhecido como gráfico de Ramsay (1967). Linhas cheias, paralelas à diagonal principal (condição de plane strain) representam isovalores de perdas volumétricas (Ramsay \& Wood 1973). Os valores dos elipsódes constantes da tabela 1 ajustam-se a uma reta (tracejada), cujo gradiente é menor que a unidade. A continuar este padrão, poder-se-ia interpretar esse efeito como perda incremental de volume quase que idêntico ao incremento do encurtamento. Veja o texto para as devidas explanaçóes Figure 3 - a. Stereogram (lower hemisphere) showing the attitudes of the principal axes of the ellipsoids represented by data in table 1 . Captions represent the principal axes of each ellipsoid. Dashed lines plot the attitudes of local mylonitic foliations. Lm represents the attitudes of mineral lineations. b. Flinn (1962) diagram shown with logarithmic scale (Ramsay 1967). Whole lines parallel to the main diagonal (plane strain) represent contours of volume loss (Ramsay \& Wood 1973). The ellipsoids calculated in this study plot along a (dashed) line with a gradient less than one. See text for explanations

contém duas linhas desprovidas de extensäo finita (no finite elongation) em virtude de as mesmas serem oriundas da interseção entre a elipse e o círculo (original) de mesma área. Como se verifica na figura em questão, uma dessas duas linhas marca precisamente a direção de cisalhamento, estando o vórtice, isto 6 , o sentido do movimento cisalhante, indicado pelo ângulo agudo $\theta^{\prime}$ (vergência) formado entre o eixo maior da elipse e esta direção de cisalhamento.

Pode-se fazer a mesma analogia para a figura $4 \mathrm{~b}$, levandose em conta que nos três elipsóides obtidos nesse estudo os ângulos de caimento dos eixos principais de deformação, maior e menor ( $\mathrm{X} \mathrm{e} \mathrm{Z}$ ) têm baixos valores. Desta forma podese trabalhar com as seçōes $X Z$ de cada qual, de modo a permitir a dedução do sentido do movimento nessa franja de deformação milonitica.

Em primeiro lugar determinam-se os valores dos ângulos $\theta^{\prime}$ conforme define a figura 4b. Para facilidade de entendimento de nossas idéias, de modo a realçar as inerentes implicações geométricas, decompöe-se o conjunto da figura $4 \mathrm{~b}$ nos dois esquemas das figuras $5 b$ e c. As seçöes $\mathrm{XZ}$, nas figuras
$5 a, b$ e c, têm elipticidade na proporção de $5,32: 1$, dado que esta é a razão encontrada na amostra número III, a qual se aproxima do valor da seção $\mathrm{XZ}$ da amostra número $\mathrm{I}$.

Depreende-se, então, que a escolha de uma das figuras 5 deverá recair sobre aquela que puder reunir maiores similaridades com o quadro estrutural encontrado na área em pauta. Se a escolha for para o diagrama da figura $5 b$, implicará movimento de blocos com natureza dextrógira e potenciais direçöes de movimento cisalhante segundo a direção N60E. No caso de a escolha recair no conjunto da figura $5 \mathrm{c}$, inverte-se o sentido do movimento relativo dos blocos para levógiro e a direção de cisalhamento indicaria que os movimentos teriam ocorrido ao longo da direção N13E.

$O$ estereograma da figura $3 a$ exibe as atitudes de umas poucas lineaçốes e foliaçōes miloníticas medidas nos pontos de coleta das amostras para as determinaçōes em questáo. Como se pode verificar, a tendéncia é a de concentrar as atitudes dessas estruturas locais ao redor da direção N60E.

Diagramas de lineações tomadas de outros trabalhos específicos dessas particulares zonas deformadas (Barbosa et 


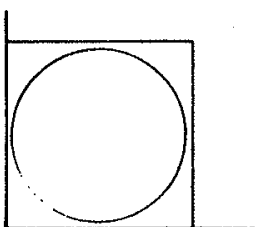

(a)

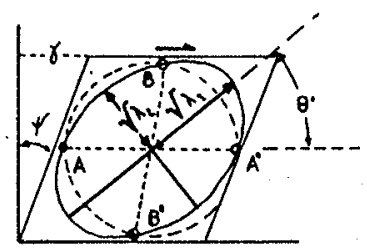

(b)
Figura 4 - Deformação por mecanismo de cisalhamento simples. a. $O$ circulo inicial deforma-se em uma elipse b. elipse de mesma área, com semi-eixos de magnitudes iguais a V $\lambda_{1} e$ $\checkmark \lambda_{2} . O$ ângulo agudo $\theta^{\prime}$ denota a natureza dextrógira do movimento relativo. Linhas sem elongação finita $A A^{\prime} e B B^{\prime}$ são pertinentes ao ctrculo e d elipse. $O$ deslocamento relativo $e$ efetuado ao longo da linha sem elongação $A A^{\prime}$ e constitui a direção de cisalhamento. $\psi$ é a deformação cisalhante angular enquanto $\gamma$ é a correspondente deformação cisalhante dada pela relação $\gamma=\operatorname{tg} \psi$

Figure 4 - Deformation by simple shear mechanism. a. The original circle deforms into $b$. an ellipse of same area, whose semi-axes have magnitudes $\sqrt{\lambda_{1}}$ and $\sqrt{\lambda_{2}}$. The values of angle $\theta^{\prime}$ denotes a dextral sense of movement. $\mathrm{AA}^{\prime}$ and $\mathrm{BB}^{\prime}$ are the lines of no finite elongation. $\mathrm{AA}^{\prime}$ is the shear direction. $\psi$ represents the angular shear strain which is given by $\gamma=\tan \psi$

al. 1981, Fig. 53-b, Campanha 1981, Fig. 3d) têm máximos sub-horizontais (coincidentemente) na direção N60E.

Cabe aqui ressaltar que o quadro acima é por demais simplista e foi assim composto com a finalidade precípua de permitir uma primeira aproximação para o complexo quadro real. A elipticidade usada nas figuras 5 aproxima-se bastante de dois dos três casos reais. Foram usadas as direções das linhas sem elongaçōes finitas como referenciais às direções de cisalhamento e tambem como indicadoras das orientaçöes (mas não à localização) das margens ou bordas da zona de cisalhamento. Na realidade, essas linhas sem elongaçáo pertenceriam às superfícies (imaginárias como é o caso das bordas) cujo caso particular seria o que comumente se chama de plano de cisalhamento. Finalmente, o angulo agudo $\theta^{\prime}$ foi acima calculado para a aplicação em um hipotético caso de mecanismo de deformação por cisalhamento simples. Tal situação implicaria a invariabilidade volumétrica, tampouco admitiria os efeitos da existência de anisotropias pretéritas nem o conluio com outros mecánismos concomitantes no desenvolvimento de estruturas nessa zona de deformação.

A realidade dos fatos geológicos parece distinta da inicialmente representada nas figuras 4 e 5 , uma vez que se impóem dificuldades adicionais. Dessa forma fez-se então uma segunda aproximação cujos passos serão descritos.

Como se depreênde dá tabela 1 , os sólidos ali referenciados representam elipsóides finais, produtos, na acepção literal da palavra, de tramas pretéritas por mecanismos deformacionais que representam as tramas tectônicas (strain). Também verifica-se nesta tabela que os elipsóides têm valores $k$ (Flinn 1962, parâmetro classificador de forma) diferentes 'de $1 \mathrm{e}$, conseqüentemente, também distinto da condição de plane-strain, o que invalida aquele resultado para o ângulo $\theta_{x z}^{\prime}$ determinado na abordagem precedente.

Os elipsóides encontrados evidenciam uma aparente perda volumétrica. Havendo ou não uma real perda de volume durante a deformação, o fato é que se devem adequar os valores daquelas relações angulares, que figuram na tabela 1 , e podem ser comparados com os valores precedentes obtidos para um regime sem variação volumétrica. As fórmulas para tais avaliaçōes são simples e estão relacionadas na parte inferior da tabela.

A relação [1] permite calcular o valor de $\theta_{x z}^{\prime}$, que repre-

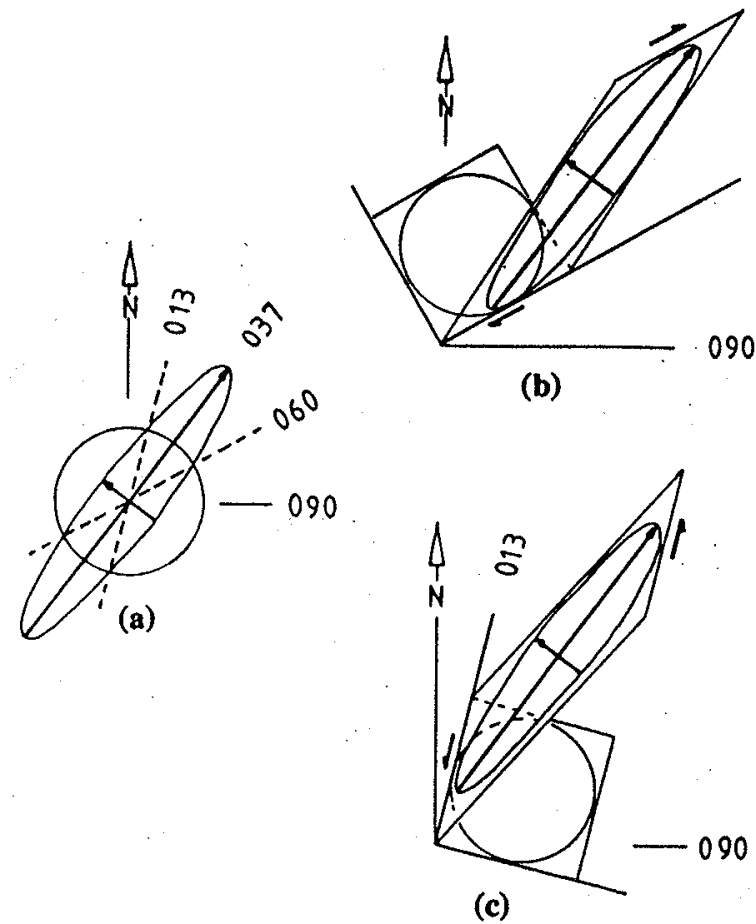

060

Figura' 5 - a. Seção $X Z$ do elipsóide encontrado para a amostra número III: elipticidade $R=5,32$, eixo maior principal $(X)$ com caimento sub-horizontal para o azimute $37^{\circ}$. Tomando-se por base a orientação geográfica dessa seção, verifica-se que a mesma possui duas linhas sem elongações finitas orientadas segundo N13E e N60E. b. Primeira possibilidade: deformação por cisalhamento simples, segundo a direção N6OE e movimento de natureza dextral, produz a seção com orientação e elipticidade ilustrada na figura $5 a$. c. Segunda possibilidade: deformação por cisalhamento simples, segundo a direção NI $3 E$, produz também a orientaçâo e a elipticidade da figura $5 a$, desde que o movimento relativo seja de natureza levógira Figure 5-a. Section XZ of the calculated ellipsoid for sample no. III, ellipticity $R=5.32$, the main principal axis $(X)$ plunges at a very low angle towards the azimuth $37^{\circ}$. The lines of no finite elongation are oriented along. N13E and N60E directions, respectively. b. First possibility: simple shear deformation along the shear direction $\mathrm{N} 60 \mathrm{E}$ and dextral movement sense. c. Second possibility: simple shear deformation along shear line oriented along N13E direction, with a sinistral movement sense

senta aquele ângulo ilustrado na figura $4 b$ e $R_{x z}$, que constitui a elipticidade daquela seção. Calcula-se a deformação cisalhante $\gamma_{x z}$ (shear strain) pela relação [2] e, a partir desta, reconhece-se o valor da deformação cisalhante angular $\psi_{x z}$ usando-se a relação [3]. Os valores de $\gamma_{x z}$ e $\psi_{x z}$ para os trếs elipsóides estão também relacionados na tabela 1 .

Existem várias relações para se determinar a aparente variação volumétrica - uma das mais simples é dada por [4]. $\Delta$ é a porcentagem da variação volumétrica indicada por valores que podem ser positivos, iguais a zero ou negativos, consoante o caso de aumento, nấo variaçáo ou perda de volume, respectivamente. Decorrente da variação volumétrica, aquele ângulo $\theta_{x z}$ passa para um novo valor, aqui representado por $\phi_{x z}^{\prime}$ na tabela 1 e obtido segundo a relação [5], na qual $\lambda_{1}$ e $\lambda_{3}$ são, respectivamente, as elongações quadráticas principais, maior $\mathrm{e}$ menor, neste caso normalizadas relativamente ao valor do eixo principal intermediário $\sqrt{\lambda_{2}}$ de cada elipsóide.

De posse dos valores de $\Delta \mathrm{e} \phi_{x z}^{\prime}$, faz-se uso da relação [6], 
Tabela 1 - Dados de deformação obtidos a partir da forma de fitas de quartzo em rochas miloníticas. Consultar o texto para detalhes $e$ as devidas referências. Fórmulas, também referenciadas no texto, foram usadas para o cáculo da variação nos ângulos $\Theta^{\prime} e$ \$, consoante a possível variação volumétrica, conforme a análise de deformação elaborada neste artigo

Table 1-

\begin{tabular}{|c|c|c|c|c|c|c|c|c|c|c|c|c|c|c|c|}
\hline \multirow{3}{*}{$\begin{array}{c}\text { Amos. } \\
\text { №. }\end{array}$} & \multirow{3}{*}{$\begin{array}{c}\text { IGE } \\
\%\end{array}$} & \multirow{3}{*}{$\begin{array}{c}\text { Proporçōes } \\
\text { nos Eixos } \\
X: Y: Z\end{array}$} & \multirow{2}{*}{\multicolumn{3}{|c|}{$\begin{array}{l}\text { Porcentagem de } \\
\text { Distorção \% }\end{array}$}} & \multirow{3}{*}{$\begin{array}{c}\text { Parâmetro } \\
\text { Flinn } \\
\mathbf{k}\end{array}$} & \multicolumn{2}{|c|}{ Deformação } & \multicolumn{6}{|c|}{ Parâmetros } & \multirow{3}{*}{$\begin{array}{c}\text { Var. } \\
\text { Vol. } \\
\%\end{array}$} \\
\hline & & & & & & & \multirow{2}{*}{$\begin{array}{c}\text { Nadai } \\
\boldsymbol{\varepsilon}_{\mathrm{s}}\end{array}$} & \multirow{2}{*}{$\begin{array}{c}\text { Ramsay } \\
\text { d }\end{array}$} & \multicolumn{3}{|c|}{ s/var. vol. } & \multicolumn{3}{|c|}{ c/var. vol. } & \\
\hline & & & $\mathbf{X}$ & $\mathbf{Y}$ & $\mathbf{Z}$ & & & & $\theta_{x z}^{\prime}$ & $\gamma_{x z}$ & $\psi_{x z}$ & $\phi_{x z}^{\prime}$ & $\gamma_{x z}$ & $\psi_{x z}$ & \\
\hline 2 & 2 & & & & & & & & & 1, & & & & 5 & -74 \\
\hline 5 & 1 , & & 145 & 88 & & & 1 , & 7 & 5 & 3, & 71 & 4 & 0 & 39,6 & -85 \\
\hline 6 & 15,6 & $5,3: 4,2: 1$ & 88,6 & 49,6 & $-64,6$ & 0,080 & 2,28 & 3,23 & 83,4 & 1,9 & 61,9 & 8,4 & 0,7 & 38,7 & -70 \\
\hline
\end{tabular}

$$
\begin{aligned}
\theta^{\prime} & =\operatorname{arctg}[1 / \mathrm{R}]^{1 / 2} \\
\gamma & =2 / \operatorname{tg} 2 \theta^{\prime} \\
\psi & =\operatorname{arctg} \gamma \\
1+\Delta & =\mathrm{XZ} / \mathrm{Y}^{2} \\
\operatorname{tg} \phi^{\prime} & =\frac{\lambda_{3}\left(\lambda_{1}-1\right)}{\lambda_{1}\left(1-\lambda_{3}\right)} \\
\operatorname{tg} 2 \phi^{\prime} & =\frac{2 \gamma(1+\Delta)}{1+\gamma^{2}-(1+\Delta)^{2}}
\end{aligned}
$$

[4] Sendo $X=\sqrt{\lambda_{1}} ; Y=\sqrt{\lambda_{2}}$ e $Z=\sqrt{\lambda_{3}}$ a qual, mediante manipulação trivial de desdobramento, conduz a uma equação do segundo grau. Obtêm-se af duas raízes $\gamma_{1}$ e $\gamma_{2}$ que I. satisfazem plenamente à relação [6] e II. possivelmente têm valores distintos entre si e (provavelmente) diferentes do de $\gamma_{x z}$, calculado previamente para o caso em que $\triangle=0$.

Matematicamente, está claro que as soluções $\gamma_{1}$ e $\gamma_{2}$ satisfazem à relação [6] em termos de $\phi_{x z}^{\prime}$ e $\Delta$, entretanto ś uma daquelas raízes tem significado geológico. Em outras palavras, s6 um daqueles valores de $\gamma$ reproduz com exatidão aquela proporcionalidade nos eixos (X : Y : Z) encontrada por este estudo (e listada na Tab. 1). A verificação dos valores proporcionais daqueles eixos foi obtida por um programa auxiliar de computador que simula superposições de tramas tridimensionais - isto $\epsilon$, deformações, mecanismos e variações volumétricas - e fornece não só as magnitudes finais bem como as orientaçöes desses eixos principais.

Para o caso de se lidar com tramas em duas dimensões (por exemplo, o plano $\mathrm{XZ}$ ), pode-se usar uma solução gráfica (Sanderson 1982, Ramsay \& Huber 1983, Fig. 3-20). Nos casos apresentados no presente estudo isto não foi possível em virtude de seus valores estarem fora dos limites representados por aqueles gráficos. Esta é uma das razões de se optar por aquela simulação numérica descrita.

\section{DISCUSSÃO E CONCLUSÕES O ponto inicial dessa} discussão refere-se à natureza das fitas de quartzo, as quais são onipresentes nos vários setores assinalados na figura 2. Essas fitas são observadas não só em diferentes litologias como também em domínios com distintas intensidades de deformaçōes.

A análise das formas dos sólidos em questão demonstra que aquelas supostas feiçôes, descritas anteriormente como lineações minerais, veramente são feições aparentes, pois resultam da interseção de sólidos com formas discóides (Campanha \& Ferrari 1984), co-planares com a foliação milonítica, por particulares superfícies de observação.

Observações em lâminas delgadas comprovam que esses extensos ribbons são constituídos por mais de um grão de quartzo e que inexistem aquelas feições típicas de recristalização dinâmica: extinção ondulante, subgrãos ou clusters de subgrãos, novos grãos, lamelas e bandas de deformação. $\mathrm{Na}$ verdade, a aparência dessas fitas se assemelha muito à dos chamados plattenquartz (compare as figuras 2-59-a e 2-59-b de Bard 1980, com a Fig. 6b aqui ilustrada). Ou seja, esses ribbons são conjuntos de cristais, cada qual com contornos sub-retangulares, cujas variações nas orientações cristalográficas não foram ainda investigadas.

Em contrapartida, nota-se que os ribbons desta região de estudo também têm muita semelhança morfológica com os descritos por Simpson (1983), ocorrendo em rochas granito-gnáissicas localizadas em zonas de cisalhamento dos Alpes suíços. Os citados ribbons são constituídos de policristais com formas sub-retangulares e claramente são também desprovidos daquelas características que denunciam recristalização dinâmica. É notável a existência de grande semelhança na morfologia das tiras de quartzo do presente estudo com as ilustradas pelas fotomicrografias das figuras $8 \mathrm{e}$ 9 de Simpson (1983).

Na concepção de Simpson (1983, esquema da Fig. 10), essas fitas teriam gênese a partir da deformação progressiva de agregados de grãos de quartzo e ainda na superfície de separação dessas fitas, denominadas planos- $F$, dispõem-se minerais félsicos e máficos de grã muito mais fina que a do quartzo componente daqueles ribbons.

Os esquemas das figuras $6 \mathrm{a}$ e $\mathrm{b}$ do presente estudo têm aqui propositos de comparações de texturas. Essas microestruturas foram traçadas a partir de projeções de lâminas delgadas de amostras coletadas, respectivamente, em zonas exterior e interior da faixa de milonitização que passa pelo setor G. A figura $6 \mathrm{~b}$ ilustra um domínio da lâmina da amostra número II. Aventa-se a hiṕtese de que esta particular textura possa, na verdade, constituir um estágio mais avançado de deformação do que o representado pela figura 10 de Simpson (1983).

Vale assinalar que em lâminas delgadas não se encontraram 
ribbons de outra fase mineral que não fosse a do quartzo. Constata-se também a ausência dessas tiras naquelas lâminas delgadas, as quais denotavam porcentagem mais elevada de filossilicatos. Aliás, a litologia mais propícia ao desenvolvimento dessas tiras de quartzo parece ser a de rochas félsicas, com composição predominantemente quartzo-feldspática ou então em outra litologia qualquer, a qual reúna condições de acondicionar a massa de quartzo entre interfaces constituídas de feldspatos.

A última observação do parágrafo acima $\in$ fruto das constataçōes feitas em diversas amostras. Os ribbons de quartzo, como já se descreveu, são observados a vista desarmada devido à aparência fitada, aspecto translúcido, entremeados em fína massa, geralmente félsica e opaca. Aventa-se aqui hip6tese de a interface entre as fases quartzo e feldspato(s) ser algo inerte, ou que pelo menos essas fases foram "imiscíveis" nas condições desse particular tipo de ambiente de deformação. Devido talvez a este fato seria possível que esses grãos de feldspatos atuassem como geradores de gradiente de pressão sobre os grãos de quartzo (Hobbs et al. 1976, p. 251, e Figs. 5.28-a e b). Isso significaria a possibilidade da fluência ou o escoamento (creep) dos grãos de quartzo pelos mecanismos de deformação plástica, permitindo assim atingir as formas finais extremamente alongadas que aqui observamos (Fig. 6b).

Uma possível explicação para a clara inexistência daquelas feições características de recristalização dinâmica seria atribuir tais fatos a efeitos oriundos de evento(s) termal(is) posterior(es) à deformação principal, permitindo assim um crescimento (neomineralização) dos grãos e/ou completa eliminação daqueles defeitos planares já mencionados. Para muitos, o termo blastomilonito teria aqui essa conotação claramente genética. Entretanto não há ainda uma uniformidade na aplicação desse termo, fato que dificulta ainda mais o uso da controvertida nomenclatura desses tipos de rochas.

O termo blastomilonito não deveria ser usado para diferenciar milonitos com matriz de grãos mais grossos daqueles que possuem matriz mais fina (White 1982). Estudos experimentais (Mercier et al. 1977, Twiss 1977) de paleopiezometria (White 1979) concluíram que para um determinado mineral o tamanho do grão da matriz (recristalizada) é muito mais dependente do stress e da taxa de deformação (strain rate) e muito menos dependente (isto $\epsilon$, controlado) ou função da
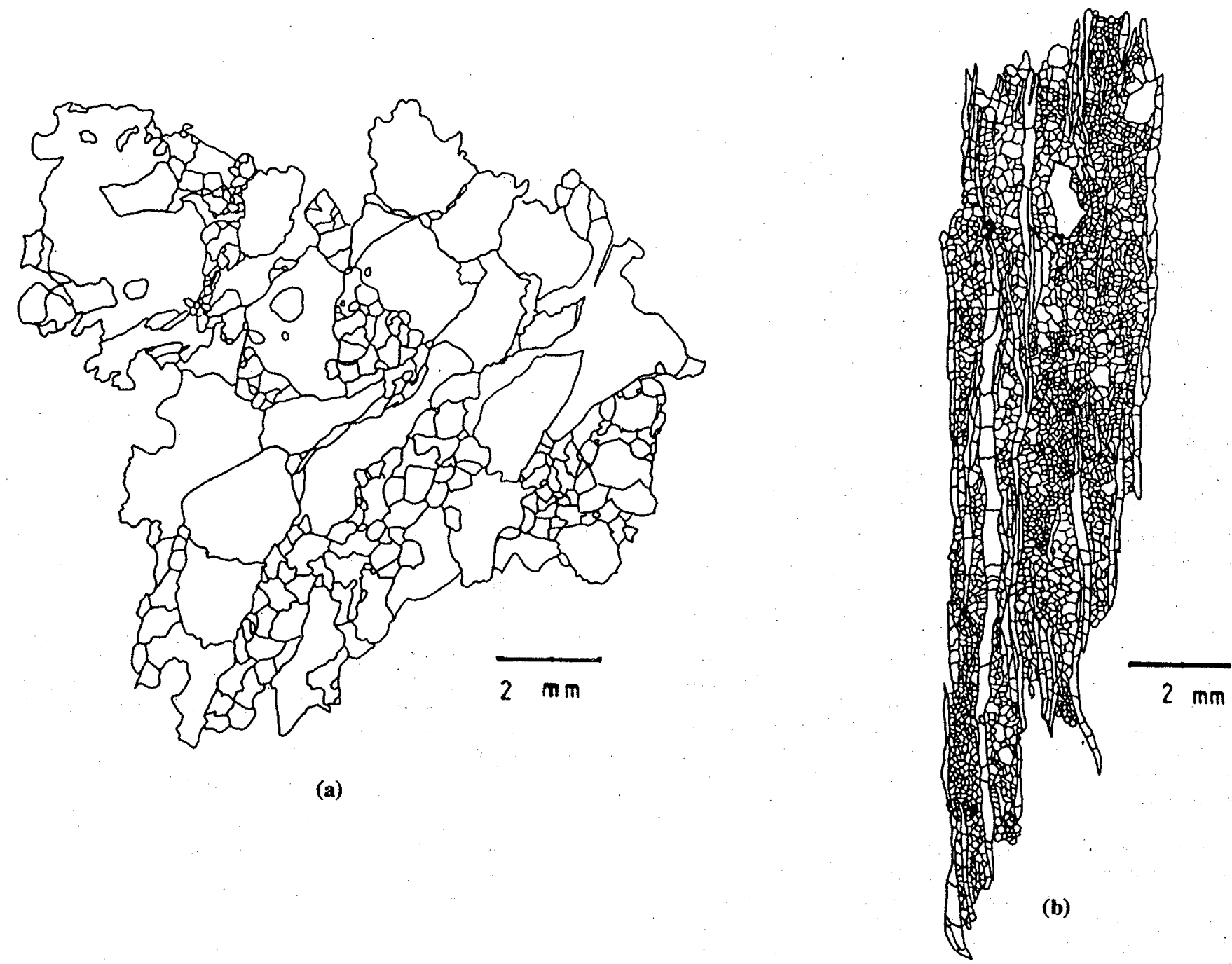

Figura 6-a. Microestrutura observada em rocha exterior às duas zonas de milonitização. Traçado efetuado a partir da projeção de seção delgada. b. Microestrutura observada em seção delgada efetuada perpendicularmante à foliação milonítica da amostra número II (consultar os dados na Tabela 1). Os filetes extremamente alongados constituem as fitas (ribbons) de quartzo mencionadas no texto. $O$ traçado desta figura também foi efetuado diretamente da projeção de lâmina delgada

Figure 6-a. Microstructure, traced from thin section, of a sample collected away from the main mylonitic zones. b. Microstructure taken from a thin section cut perpendicular to the mylonitic foliation of sample no. II (see data in table I). The nature of the extremely elongated quartz ribbons is discussed in the text 
temperatura (White 1982, p. 216).

As alegaçốes de White têm de alguma forma conexão com o problema ora em discussão, e portanto fazem algum sentido. Caso o papel da elevação da temperatura, advinda de qualquer evento termal, fosse precisamente o de aumentar o tamanho dos grãos, surgem de imediato duas questōes: I. por que razão(ões) este aumento só se verificaria, e com distintas intensidades, ao longo de um particular plano, o da foliação milonítica? II. Qual a razão para a existência de tal anisotropia ao longo desse plano?

Ainda refletindo sobre esse assunto, essas neomineralizaçóes, às expensas do aumento do gradiente térmico, consistiriam, em essência, na eliminação dos chamados high angle boundaries entre preteritos novos grãos. Potencialmente, essas eliminações poderiam (ou deveriam ?) ocorrer em qualquer direção em vez de ficarem limitadas aos planos da foliação milonítica, como invariavelmente se observa nas lâminas delgadas.

Em trabalho recente, Van Den Driessche \& Brun (1987) atribuem o grande elongamento de feldspatos (rolling structures) a mecanismos de giro e estiramento, em regime de deformação por cisalhamento simples. De maneira análoga, aventase aqui a hipótese de que a gênese dessas fitas de quartzo esteja ligada à deformação do grão, ou de agregado de grãos de quartzo, em condições àmbientais genericamente denominadas de high grade shear zones (Simpson 1983). Ainda, tal qual Van Den Driessche \& Brun (1987), a magnitude dos estiramentos das partículas, ribbons, deve relacionar-se à intensidade da deformação sofrida por essas rochas.

$O$ segundo ponto a ser aqui discutido refere-se à natureza do(s) movimento(s). De acordo com explanação já feita, todos os elementos estruturais encontrados nos diversos setores descritos conduzem para um quadro de movimentos ao longo de superfícies verticais e do tipo transcorrente. Aparentemente não teríamos como justificar os movimentos na zona de cisalhamento, no sentido levógiro, tomando por base o modelo idealizado na figura $5 \mathrm{c}$, visto que o quadro das estruturas locais não se coadunaria com as desta figura. Em outras palavras, os poucos dados geológicos plotados na figura $3 \mathrm{a}$ estão mais conexos com o desenvolvimento de estruturas pelo esquema da figura $5 b$, não só devido às posiçōes das feiçōes lineares, mas principalmente pela atitude das superfícies limítrofes ou bordas da zona de cisalhamento, na direção ENE-WSW. O modelo da figura $5 c$ posicionaria tal superfície segundo a direção NNE-SSW, o que não condiz com as evidências locais.

Constata-se, pois, que o sentido do movimento (vórtice) 6 de natureza dextrógira com superfícies de cisalhamento praticamente verticais. Isso corrobora as deduções, feitas já há alguns anos por outros autores, tendo por base evidências de cunho regional e, portanto, de natureza totalmente distinta da que aqui se apresenta (por exemplo, Almeida et al. 1975).

Outro fato merecedor de menção $\varepsilon$ referente aos valores da deformação cisalhante $\gamma$ e sua correspondente angular $\psi$. Em termos do valor das elipticidades das seções $\mathrm{XZ}$ dos elipsóides da tabela 1 , teríamos resultados razóneis para $\gamma$ não fossem os efeitos da aparente variação volumétrica que ocasionou a redução de $\gamma$, conforme lista a tabela 1 . Claramente, baixos valores para $\gamma$ ou $\psi$ implicam em primeira instância baixos valores nos rejeitos direcionais componentes do rejeito total.

Por outro lado, não parece correto aceitar-se que os valores de $\theta_{x z}^{\prime}$ sejam realmente da ordem de $16^{\circ}$ a $24^{\circ}$ de acordo com a tabela 1 . O efeito de uma aparente mudança volumétrica reduziria esses ângulos para aqueles limites entre $4,2^{\circ} \mathrm{e}$ $8,4^{\circ}$, valores que parecem mais condizentes com o extremo paralelismo das estruturas ao longo dessa faixa de deformação localizada.

Observando-se atentamente a figura $3 \mathrm{a}$, constata-se que os eixos dos elipsóides encontrados fazem grandes ângulos com as foliações miloníticas medidas no campo. A razão por que os três eixos $\sqrt{\lambda_{1}}$ encontrados não têm uma atitude mais próxima da foliação milonítica, como era de esperar, talvez possa ser justificada pelos erros inevitáveis introduzidos durante a orientação e a coleta da amostra no campo, aliados ao posterior giro para a posição geográfica. Infelizmente não há como minorar esses possíveis erros uma vez que a bússola de geb́logo é um instrumento aquém da precisão aqui requerida. Em casos de grandes deformaçōes, os prováveis erros de uns poucos graus (por exmplo, $5-10^{\circ}$ ) são cruciais, pois podem implicar o aumento do valor da razão de strain (Rs) da ordem de 10 para 100 !

Finalmente, acerca da separação relativa entre os blocos com base nos elipsóides encontrados, é preciso levar em conta os seguintes fatores: $I$. as tramas obtidas, caso consideradas como representativas de deformação (isto é, elipsóides de deformação) não representariam as tramas tectônicas das regiōes de coleta das amostras. Na verdade, seriam tramas finais, produtos de strain tectônico sobre trama pretérita. Certamente, existiria uma trama preterita, pois as rochas locais são de natureza gnáissico-migmatíticas:' II. os elipsóides obtidos são razoavelmente consistentes no contexto da estrutura local. Entretanto, não se logrou completar um perfil ortogonal a esta zona deformada, como seria desejável, para as almejadas deduçōes. É possível, pois, que no futuro se encontrem medidas com valores mais elevados, os quais reflitam deformações de maior magnitude ao longo dessa zona; III. as tramas finais nessas rochas denotam que estas são quase desprovidas da característica stretching direction lineation, muito comum em inúmeras descrições de famosas zonas de cisalhamento.

A trama mesoscópica (amostras de mão) já denota o que se confirma ao microscópio pela análise da forma dos grãos: trata-se de um proeminente tectonito-S. Portanto, alguma acomodação da deformação ao longo da provável direção principal intermediária de strain - argumento amplamente discutido em termos de compatibilidade de strain, especialmente em regimes de falhas de empurrão, por motivo de espaço, seria nesse contexto permissível dado que aqui essa acomodação se verificaria em uma direção vertical ou próximo dessa condição.

Em suma, confirma-se a hipotese do sentido dextral do(s) movimento(s). Não temos possibilidades, ainda, de quantificar deslocamentos.

Outro aspecto de interesse relaciona-se às formas discóides encontradas para os ribbons de quartzo. Uma inspeção nos resultados da tabela 1 e figuras 3 leva a concluir que, apesar do número limitado de análises, as mesmas apresentam consistência na orientação dos eixos dos elipsoides e também na forma extremamente oblata dos mesmos. A constatação no campo de que a amostra de número III é relativamente menos deformada que a de número II encontra respaldo nas quantificações efetuadas. Infelizmente, não se dispõem ainda de outros resultados, quer sejam desta faixa milonítica aqui analisada ou daquela que, hipoteticamente, passa paralelamente ao sul e inclui as rochas do setor B (Fig. 2).

Os resultados para os valores no parâmetro $k$ de Flinn (1962), que caracteriza a forma dos elipsóides, oscilam entre 0,04 e 0,08 . Tais resultados podem ser oriundos de diversos fatores, ate como já se afirmou, de uma aparente variação volumétrica (Ramsay \& Wood 1973). Os efeitos denominados de apparent flattening decorrem de processo oriundo do encurtamento ao longo do menor eixo principal de strain $(Z)$ sem que no entanto esse shortening seja suficientemente compensado por apropriado estiramento ao longo do eixo maior (X) do elipsớide em questão. Em outras palavras, essa aparente incapacidade de compensaçóes ao longo das duas direções discriminadas pode ser comparada aos efeitos sofridos por uma esponja quando comprimida em uma direção. $O$ resultado é a deformação ser parcialmente compensada pela I. redução no volume (dos poros) e II. por algum estiramento em dire- 
ção(ões) ortogonal(is) à direção de compressão (Ramsay \& Wood 1973, Mawer 1983).

Uma rápida manipulação com aqueles valores encontrados para as razóes entre os eixos dos elipsoides da tabela 1 leva a admitir uma perda volumétrica na ordem de $70,1 \%$ à $85,1 \%$. As implicações mecânicas dos resultados em pauta são muito sérias em face de os valores acima serem excessivamente altos. Uma idéia da variação volumétrica relativa ao quartzo poderia ser obtida medindo-se sistematicamente os volumes dos mesmos dentro e fora das zonas de cisalhamento. Estudo dessa natureza ainda não foi efetuado. Outra forma de averiguar seria a de buscar evidências microestruturais, ou seja, verificar a presença e a extensão de mecanismos de difusão, como sombras de pressão, que justificassem tais cifras. Aparentemente, as sombras de pressão existentes nas lâminas não teriam valores suficientes para corroborar essas perdas volumétricas. Outro critério microestrutural seria o de aceitar o modelo proposto por Vouchez (1980) para a progressiva deformação e recristalização dos grãos ou agregados de grãos de quartzo, os quais são incorporados (mantle, White 1976) à matriz, enquanto o núcleo restante (core, White 1976) deforma-se por mecanismos de plasticidade intracristalina.

Mecanicamente, a perda de volume em pauta deveria ser facilmente notada pelas evidências de difusão de quartzo em domínios exteriores às zonas de deformação localizadas. $\mathrm{Ou}$ seja, veios de quartzo, leitos diferenciados etc. deveriam ser observados em abundância, e os autores não têm notícia, até esta data, da existência de tais quantidades.

Existem evidências da introdução de material nas rochas aflorantes no setor C. Entretanto, I. não se tem certeza se este setor é de fato um domínio exterior às zonas de cisalhamento principais; II. caso o seja, não se têm afloramentos contínuos e externos às demais zonas de cisalhamento que pudessem atestar a veracidade dessa afirmação.

Uma outra possibilidade seria admitir que as tramas observadas resultam da superposição de tramas (isto $\epsilon$, deformaçōes) sucessivas oriundas de variados mecanismos, graus de homogeneidades, intensidades e orientaçōes (consulte Sanderson 1976). Em outras palavras, as tramas finais observadas (exemplos: mullions, rods, discos de quartzo etc.) não devem ser confundidos com a real trama tectônica.

Alguns autores reputam as zonas miloníticas como sendo formadas em resposta à combinação de mecanismos definidos explicitamente como progressive inhomogeneous simple shear and inhomogeneous bulk flattening (Hossack 1968, Coward 1976). Outros autores caracterizam as zonas miloníticas como domínios de non co-axial laminar flow (Lister \& Snoke 1984), em que o mecanismo de cisalhamento simples seria apenas um tipo dee strain não co-axial neste contexto. Ainda deve-se ter em mente o fato de os modelos usados aqui serem sempre extremamente simplistas se comparados com a complexidade dos movimentos $\mathrm{e}$ as restrições (constraints) mecânicas impostas pela natureza.

Poder-se-ia ainda explicar algumas outras estruturas aqui descritas da seguinte forma:

I. Os discos de quartzo resultariam de deformação não coaxial - cujos eixos principais de strain, maior e menor, seriam sub-horizontais - seguido de flattening perpendicular à zona de deformação, o qual seria oriundo de zonas locais do tipo transpressional (vide o conceito de transpression segundo a abordagem do ponto de vista deformacional de Sanderson \& Marchini 1984), fruto da interação entre a direção de movimento com a morfologia da superfície de falha.

II. Evidências de movimentos verticais, talvez em épocas pósmilonitização, seriam constatadas pela rotação de elementos ao longo de planos verticais (setor E, Fig. 2), como se descreveu. Também já se mencionou na "Introdução": aqueles lineamentos que ramificam assintoticamente, rumo a norte, em direção aos Estados do Espírito Santo e de Minas Gerais, a partir das localidades de Itaocara, Além-Paraíba etc. podem constituir um domínio transpressional (Woodcock \& Fischer 1986), considerando que o movimento ao longo da ZCRPS é de natureza dextral. Em outras palavras, aquelas curvas assintóticas constituiriam a região que anteriormente se definiu como restraining bends. Nessas regiốes produzir-se-iam movimentos ascensionais de blocos por efeitos de transpressão.

III. Estruturas descritas anteriormente como mullions podem ser perfeitamente explicadas como sendo tramas prolatas oriundas da superposição de strain tectônico não co-axial, cujos planos de cisalhamento seriam subverticais, sobre trama planar preterita dada por uma foliação da natureza composicional (aleitamento ou bandamento gnáissico) com atitude sub-horizontal. Esta trama seria aqui tratada como uma anisotropia tipo compactação ou aparente perda de volume na direção vertical (Sanderson 1976) e aqui representada esquematicamente pelas figuras $7 \mathrm{a}, \mathrm{b}$ e $\mathrm{c}$.
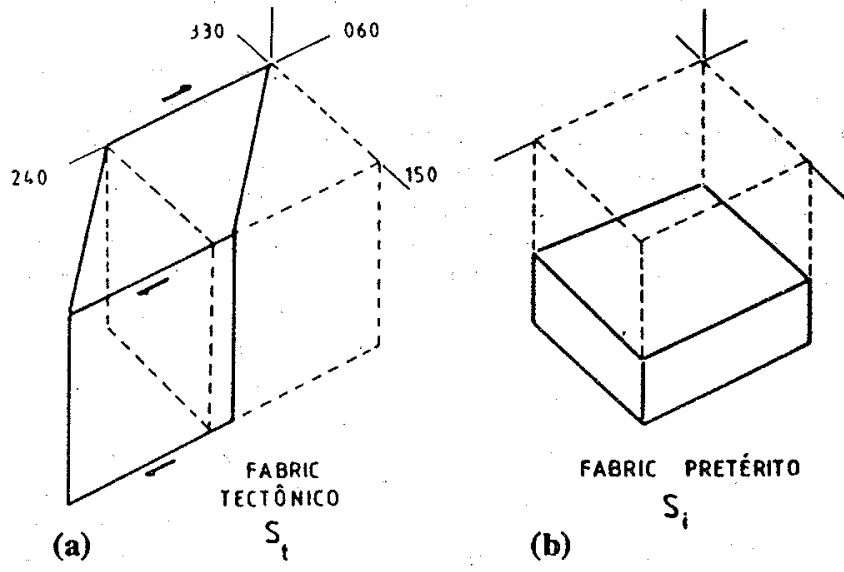

FABRIC PRETÉRITO

$S_{i}$

(b)

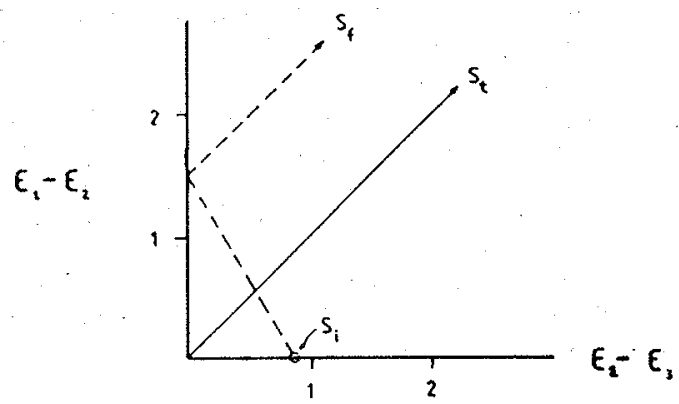

(c)

Figura 7 - a. Ilustra o caso de deformação por mecanismo de cisalhamento simples segundo a direção (de shear) N60E, em planos com atitudes verticais. Trama tectônica (St) de hipotética magnitude. Os números referem-se às orientações geográficas. b. Ilustra a existência de trama planar pretérita (Si). c. Diagrama de Flinn (1962) em escala logarítmica. Diagonal principal (linha cheia) ilustra o caminho (Path) da deformação explanada na figura $7 a$, enquanto o tracejado constitui um hipotético caminho da deformação, neste caso a trama final (Sf), produto da superposição de St sobre Si. Esta claro neste diagrama que, em determinadas circunstâncias, a trama final ( $S f)$ entra no domínio dos elipsóides prolatos e não abandona mais esse campo. Veja o texto para explicações e discussões adicionais Figure 7 -a. Simple shear deformation along a vertical plane oriented towards the N60E direction. The tectonic fabric (St) is of hypothetical magnitude. b. Represents the initial fabric (Si). c. Logarithmic version of Flinn's diagram. Main diagonal (whole line) plots the hypothetical path of the deformation represented in figure $7 \mathrm{a}$, while the dashed line is a hypothetical path of the deformation giving rise to the final fabric (Sf), originated by superposition of St on Si. The final fabric (Sf) remains in the constrictive area of Flinn's diagram. See text for explanations 
Simulação, em computador, do modelo exposto no último item, na qual se usaram várias combinaçóes de valores de $\gamma$ (deformação cisalhante colocada em posição de permitir movimento transcorrente) e de $\Delta$ (aparente perda volumétrica), simulando compactações verticais, de modo a reproduzir existência de uma trama planar pretérita (xistosidade), sempre forneceu tramas finais prolatas com os principais eixos maiores $(X)$ perto da direção de movimento relativo e eixos menores $(Z)$ quase ortogonais ao plano de cisalhamento, ambos no plano horizontal. Este quadro, aparentemente, se coadunaria perfeitamente com a formação dos chamados fold mullions pertinentes ao setor $F$.

Agradecimentos Os Autores externam seus agradecimentos ao CNPq pelas concessões de bolsas: de auxilio, aperfeiçoamento e pesquisa a $\mathrm{H}$. Dayan (processos números 402397/86-GL 300.005/82) e a J.V.A. Keller (processo nú- mero 14.2699/85-GL). Nossa gratidão também se estende à Finep especialmente na pessoa do coordenador de seus projetos junto ao Departamento de Geologia da UFRJ, Prof. Dr. Joel G. Valença, pelas inúmeras e incansáveis formas de encorajamento, incentivo e apoio material dos mais diversos; ao colega Flávio Wolff (CPRM -RJ), pela paciência na obteção das fotomicrografias que permitiram o cálculo dos primeiros strains deste trabalho; ao colega Constantino (Dino) Psomopoulos, pelo estímulo e acompanhamento nas primeiras etapas de campo; aos laminadores Washington L.G. Cruz e Tarcísio Abreu, pelas confecçōes das lâminas delgadas, em especial as orientadas; ao Profs. Drs. F.R.M. Pires e J.G. Valença e dois relatores anônimos da RBG, pelas leituras críticas e consideráveis melhorias no texto. $H$. Dayan é particularmente grato ao colega Prof. André Ferrari (UFF) pela apresentação da área e pelas primeiras viagens ao campo.

\section{REFERÊNCIAS BIBLIOGRÁFICAS}

ALMEIDA, F.F.M. 1955. As camadas de São Paulo e a tectônica da Serra da Cantareira. São Paulo, Bol. Soc. Bras. Geol., 2(4):23-40.

ALMEIDA, F.F.M.; HASUI, Y.; CARNEIRO, C.D.R. 1975. O Lineamento de Além-Parába. Rio de Janeiro, An. Acad. brasil. Ciênc., 47(3/4):575.

BARBOSA, A.L.M. \& GROSSI SAD, J.H. 1981. Projeto Carta Geológica do Estado do Rio de Janeiro, Folhas Cava, Miguel Pereira, Paralba do Sul Três Rios. Geosol-DRM, Rio de Janeiro/Belo Horizonte, $295 \mathrm{p}$.

BARD, J.P. 1980. Microtextures des roches magmatiques et metamorphiques. Masson, Paris. $192 \mathrm{p}$

BELL, T.H. 1978. Progressive deformation and reorientation of fold axes in a ductile mylonite zone Tectonophysics (44):285-320.

BERTHE, D.; CHOUKROUNE, P.; JEGOUZO, P. 1979. Orthogneiss mylonite and non coaxial deformation of granites: the example of the South Armorican Shear Zone. J. Struct. Geol. 1(1):3-42.

BRENNER, T.L.; FERRARI, A.L.; PENHA, H.M. 1980. Lineamentos estruturais no norte do Estado do Rio de Janeiro. In: CONGR. BRAS. GEOL., 31. Baln. Camboriú, 1980. Anais... Baln. Camboriú, SBG. v. 5, p.2551-2564.

BRYANT, B. \& REED, J.C. Jr. 1969. Significance of lineation and minor folds near major thrust faults in the southern Appalachians and the British and the Norwegian Caledonides. Geol. Mag., 106(5):412-429.

CAMPANHA, G.A. da C. 1980. O Lineamento de Além-Paraiba na área de Três Rios (RJ).São Paulo, 109 p. (Dissertação de Mestrado, IG/USP), (inédita).

CAMPANHA, G.A. da C. 1981. O Lineamento de Além-Paraíba na área de Três Rios (RJ). Rev. Bras. Geoc., 11(3):159-171.

CAMPANHA, G.A. da C. \& FERRARI, A.L. 1984. Lineamento de Além-Paraíba: um exemplo de zona de cisalhamento. In: CONGR. BRAS. GEOL., 33, Rio de Janeiro, 1984. Anais... Rio de Janeiro, SBG. p. 5425-5432. (Excursão Técnica)

CARRERAS, J.; ESTRADA, A.; WHITE, S. 1977. The effect of folding on the c-axis fabrics of a quartz mylonite. In: LISTER G.S.; WILLIAMS, P.F.; ZWART, H.J.; LISLE, R.J. eds. Fabrics. microstructures and microtectonics. Tectonophysics, 39:3-24.

CHESTER, F.M.; FRIDMAN, M.; LOGAN, J.M. 1986. Foliated cataclasites. Tectonophysics, 111:139-146.

COBBOLD, P.R. \& GAPAIS, D. 1987. Shear criteria in rocks: an introductory review. J. Struct. Geol., 9(5/6): 521-523.

COBBOLD, P.R. \& QUINQUIS, H. 1980. Development of sheath folds in shear regimes. J. Struct. Geol., 2(1/2):119-126.

COWARD, M.P. 1976. Strain within ductile shear zones. Tectonophysics, 34:181-197.

DAYAN, H. 1981. Deformation studies of the folded mylonites of the Moine Thrust, Eriboll District. Northwest Scotland. 439 p. (Ph.D. Thesis, Univ, Leeds) (inédita).

DAYAN, H. \& BAPTISTA FILHO, J. 1984. Caracterização de fabrics tridimensionais nos rods de quartzo da base da Serra de Carrancas, SE de Minas Gerais. In: CONGR. BRAS. GEOL., 33, Rio de Janeiro, 1984. Anais... Rio de Janeiro, SBG. v. 7, p. 3371-3380.

DAYAN, H.; BAPTISTA FILHO, J; LEITE MANSUR, R.; SABA FONSECA, M. 1987. Determinação do estado de deformação finita em quartzitos das serras de Carrancas e Bicas, SE de Minas Gerais. An. Acad. brasil. Ciênc., 59(3):203-211.

DERBY, O.A. 1880, On the age of the Brazilian gneiss series. Discovery of Eozoon. Am. J.Sci., third series, XIX:324-326.

DUNNET, D. \& SIDDANS, A.W.D. 1971. Non random sedimentary fabrics and their modification by strain. Tectonophysics. 12:307-325.

EBERT, H. 1967. A estrutura pré-cambriana do sudeste de Minas Gerais e áreas adjacentes. Curitiba. Bol. Paran. Geoc., 26:42-45.

EBERT, H. 1968. Ocorrência de fácies granulítica no sul de Minas Gerais e áreas adjacentes, em dependência da estrutura orogênica: hipóteses sobre a sua origem. Rio de Janeiro, An. Acad. brasil. Ciênc., 40:215-229 (suplemento).

ESCHER, A. \& WATTERSON, J. 1974. Stretching fabrics fold and crustal shortening. Tectonophysics, 22:223-231.

ETCHECOPAR, A. 1977. A plane kinematic model of progressive deformation in a polycrystalline aggregate. Tectonophysics, 39(1-3):121-139.

FLINN, D. 1962. On folding during three-dimensional progressive deformation. Geol. Soc. London. Quart.J., 118:385-433.

FONSECA, M.J.G.; SILVA, Z.C.G.; CAMPOS, D.A.; TOSSATO, P. 1978. Carta Geologica do Brasil ao Milionésimo, Folhas do Rio de Janeiro, Vitória e Iguape. Brasília, DNPM, $240 \mathrm{p}$.

HASUI, Y. 1983. Aspéctos geológicos essenciais da seção Caconde-Caraguatatuba e suas implicações na reconstitutição da organizaçáa e evolucão do Pré-Cambriano do leste paulista. Atas da $1^{\mathrm{a}}$ jornada sobre a Carta Geológica do Estado de São Paulo, escala 1:50.000, Pró-Minério (IPT), São Paulo.

HASUI, Y.; PONÇANO, W.L.; BISTRICHI, C.A.; STEIN, D.P.; GALVÃO, C.A.C.F.; GIMENEZ, A.; ALMEIDA, M.A.; MELO, M.S.; PIRES NETO, A.G. 1977. As grandes falhas do leste Paulista e sua importáncia. In: SIMPÓSIO DE GEOL. REG., 1, São Paulo, 1977. Atas ... Sẩo Paulo, SBG. p. 368-380.

HOBBS, B.E.; MEANS, W.D.; WILLIAMS, P.F. 1976. An outline of structural geology. J. Wiley \& Sons Inc., $572 \mathrm{p}$.

HOLMES, A. 1928. The nomenclature of petrology, 2nd ed., Thomas Murby \& Co. $248 \mathrm{p}$

HOSSACK, J.R. 1968. Pebble deformation and thrusting in the Bygdin area (southern Norway). Tectonophysics, 5(4):315-339.

LAMMERER, B. 1987. Short notes on structural section through the Ribeira Mobile Belt (Minas Gerais and Espírito Santo, Brazil); $Z \mathbf{~ b l}$. Geol. Palaont. Teil I, H. (7/8):719-728.

LISLE, R.J. 1985. Geologic strain analysis: a manual of the $\mathrm{Rf} / \phi$ technique. Pergamon Press. $100 \mathrm{p}$.

LISLE, R.J.; RONDEEL, H.E.; DOORN, D.; BRUGGE, J.; VAN DE GAAG. P. 1983. Estimation of viscosity.contrast and finite strain from deformed elliptical inclusions. J. Struct. Geol., 5(6): 603-609.

LISTER, G.S. \& SNOKE, A.W. 1984. S-C Mylonites. J. Struct. Geol. 6(6): 617-638.

LOCZY, L. de \& LADEIRA, E.A. 1976. Geologia estrutural e introdução à Geotectônica. Edgar Blücher Ltda. $528 \mathrm{p}$.

MAWER, C.K. 1983. State of strain in quartzite mylonite, central Australia. J. Strut. Geol., 5(3/4):401-410.

MERCIER, J.C.C.; ANDERSON, D.A.; CARTER, N.L. 1977. Stress in the lithosphere: inference from steady state flow of rocks. Pageogh., 115: 199-226.

OLIVEIRA, M.A.F. 1983. As faixas granulíticas da faixa Pará́ba do Sul. Rev. Bras. Geoc., 13(2):84-92.

PASSCHIER, C.W. 1986. Mylonites in the continental crust and their role as seismic reflectors. Geologie Mïmbouw, 65:167-176.

QUINQUIS, H.; ANDRESS, C.L.; BRUN, J.P.; COBBOLD, P.R. 1978. Intensive progressive shear in Ile and Groix blueschists and compatibility with subduction or obduction. Nature, 273:43-45. 
RAMSAY, J.G. 1967. Folding and fracturing of rocks. McGraw-Hill Inc.; $568 \mathrm{p}$

RAMSAY, J.G. 1980. Shear zone geometry: a review. J. Struct. Geol., 2(1/2): 83-99.

RAMSAY, J.G. 1982. Rock ductility and its influence on the development of tectonic structures in mountain belts. In: HSU, K. ed. Mountain building processes. Academic Press Inc., p. 111-127.

RAMSAY, J.G. \& ALISON, I, 1979. Structural analysis of shear zones in an alpinised Hercynian granite. Maggia Lappen, Pennine zone, Central Alps. Schweiz. min. pet. Mitt., 59:251-279.

RAMSAY, J.G. \& GRAHAM, R.H. 1970. Strain variation in shear belts. Can. J. Earth Sci., 7:786-813.

RAMSAY, J.G. \& HUBER, M.I. 1983. The techniques of modern structural geology. v. 1 - Strain Analysis. Academic Press. 307 p.

RAMSAY, J.G. \& HUBER, M.I. 1987. The techniques of modern structural geology. v. 2 - Folds and fractures. Academic Press. 700p.

RAMSAY,J.G. \& WOOD, D.S. 1973. The geometric effects of volume change during deformation processes. Tectonophysics, 13:263-277

REIS, P.A. 1982. Geologia das Folhas Três Rios, Paraíba do Sul, Miguel Pereira e Cava, RJ. In: CONGR. BRAS. GEOL., 32, Salvador, 1982. Anais... Salvador, SBG. v. 1, p. 94-102.

ROSIER, G.F. 1965. Pesquisas geologicas na parte oriental do Estado do Rio de Janeiro e na parte vizinha do Estado de Minas Gerais. Rio de Janeiro, DNPM/DGM (Boletim 222).

ROSIER, G.F. 1967. In: SCORZA E.P. Relatorio Anual do Diretor, ano de 1962, p. 23-24, DGM/DNPM, Rio de Janeiro.

RUTTER, E.H. 1986. On the nomenclature of mode of failure transitions in rocks. Tectonophysics, 122:381-387.

SADOWSKI, G.R. 1983. Sobre a geologia estrutural de cinturões de cisalhamento continentais. São Paulo, 108 p. (Tese de Livre-Docência, IG/USP). (inédita)

SANDERSON, D.J. 1973. The development of folds axes oblique to the regional trend. Tectonophysics, 16:55-70.

SANDERSON, D.J. 1976. The superposition of compaction and plane strain. Tectonophysics, 30:35-54.

SANDERSON, D.J. 1982. Models of strain variation in nappes and thrusts sheets. review. Tectonophysics, 88:201-233.

SANDERSON, D.J. \& MARCHINI, W.R.D. 1984. Transpression. $J$. Struct, Geol, 6(5):449-458.

SCHMID, S.M. 1982. Microscopic studies as indicators of deformation mechanisms and flow laws operative in mountain building. In:
HSU, K. ed. Mountain building processes. Academic Press Inc., p. 95-110.

SHIMAMOTO, T. \& IKEDA, Y. 1976. A simple algebraic method for strain estimation from deformed ellipsoidal objects. Tectonophysics, 36:315-337.

SIMPSON, C. 1983. Strain and shape-fabric variations associated with ductile shear zones. $J$. Struct. Geol., 5:61-72.

SIMPSON, C. \& SCHMID, S.M. 1983. An evaluation of criteria to deduce the shear sense of movement in sheared rocks. Geol. Soc. Am. Bull., 94:1281-1288.

TURNER, F.J. \& WEISS, L.E. 1963. Structural analysis of metamorphic tectonites. McGraw-Hill Book Co. Inc., 545 p.

TWISS, R.J. 1977. Theory and applicability of recrystallized grain size paleopiezometer. Pageogh., 115:227-244.

WHITE, S. 1976. The determination of deformation parameters from dislocation sub-structures in naturally deformed quartz. In: VENABLES, J.A. ed. Developments in electron microscopy and analysis. Academic Press, p. 505-509.

WHITE, S. 1979. Difficulties associated with paleo-stress estimates. Bull. Mineral., 102:210-215.

WHITE, S. 1982. Fault rocks of the Moine Thrust Zone: guide to their nomenclature. Textures and Microstructures, 4:211-221.

WHITE, S.H.; BRETAN, P.G.; RUTTER, E.H. 1986. Fault zone reactivation: kinematics and mechanisms. Phil. Trans. R. Soc. Lond., A.317:81-97.

WILSON, G. 1953. Mullion and rodding structures in the Moine series of Scotland. Geol. Assoc. Proc., 64: 118-151.

WOODCOCK, N.H. \& FISCHER; M. 1986. Strike-slip duplexes. $J$ Struc. Geol. 8(7):725-736.

VAN DER DRIESSCHE, J. \& BRUN, J.P. 1987. Rolling structures at large shear strain. J. Struct. Geol., 9(5/6):691-704.

VOUCHEZ, A. 1980. Ribbon texture and deformation mechanisms of quartz in mylonitized granite of great Kabylia (Algeria). Tectonophysics, 67:1-12

\section{NOTÍCIAS}

\section{SCTC INFORMÁTICA GEOLÓGICA}

A sub-comissão técnico-científica "Informática Geológica" (sCTC-INFOGEO) foi criada em agosto de 1989 no Núcleo de São Paulo/SBG para facilitar o intercâmbio entre pessoas que atuam na área das geociências, incentivando a divulgação de idéias por meio de atividades promovidas conjuntamente com o Núcleo de São Paulo/SBG (workshops, tardes de geociências, palestras, cursos etc.)

A importância dos recursos de informática no trabalho dos profissionais de Geociências fez com que a sCTC-INFOGEO fosse implantada com elevado número de interessados. Os responsáveis pela iniciatica esperam que esta se repita nos de- mais núcleos da SBG, para que seja possível a criação de uma futura comissão nacional.

A INFOGEO é coordenada por Sílvio R.F. Vlack e subcoordenada por Harmi Takita, Otto W.R. Almeida e Pedro Luiz Cortes (IG-USP); Gilberto Amaral (IG-UNICAMP), Hans D. Ebert e Ricardo Sturaro (UNESP-Rio Claro) são os representantes regionais.

Sugestōes e informações adicionais e/ou adesóes devem ser encaminhadas à sCTC INFOGEO, Caixa Postal 20897, CEP 01498, São Paulo, SP.

\section{REVISTA DO INSTITUTO GEOLÓGICO}

A Revista do Instituto Geológico da Secretaria do Meio Ambiente do Estado de São Paulo deve retomar sua periodicidade após três anos de interrupção. A Revista é editada semestralmente e mantém intercâmbio com 434 entidades, das quais 323 são estrangeiras.

O Conselho Editorial informa que, para publicação, os artigos devem estar relacionados às Geociências e áreas afins; devem ser inéditos e originais, de caráter científico e tecno16gico. A Revista também veicula comentários, críticas e réplicas de artigos, livros e qualquer tema de interesse às Geociências.

Os interessados devem enviar seus trabalhos à dra. May Christine Modenesi, Instituto Geol6gico (SMA), Avenida Miguel Stéfano, 3900, CEP 04301, São Paulo, SP. 